\title{
Комбинация плазмохимического и жидкостного травления как способ оптимизации рельефа на поверхности AIGalnN-гетероструктур
}

\author{
(С) Л.К. Марков, И.П. Смирнова, М.В. Кукушкин, А.С. Павлюченко \\ Физико-технический институт им. А.Ф. Иофрфе Российской академии наук, \\ 194021 Санкт-Петербург, Россия \\ E-mail: I.markov@mail.ioffe.ru
}

Поступила в Редакцию мая 2020 г.

В окончательной редакции мая 2020 г.

Принята к публикации мая 2020 г.

Комбинированным методом, при котором плазмохимическое травление применяется в паре с жидкостным (в растворах $\mathrm{KOH}$ или соляной кислоты), создавался рельеф на поверхности GaN, предварительно освобожденной от ростовой подложки. Изучалась зависимость получаемого рельефа от последовательности применяемых операций. Показано, что травление в растворе $\mathrm{KOH}$ с последующей стадией реактивного ионного травления обеспечивает появление на поверхности усеченных пустотелых конусов. В экспериментах также была обнаружена способность раствора соляной кислоты к травлению исключительно наноразмерных элементов рельефа $\mathrm{GaN}$, возникающих при плазмохимическом травлении поверхности. Как следствие, плазмохимическое травление образца с последующим погружением в раствор соляной кислоты создает на его поверхности объекты цилиндрической формы, переходящие в основании в конические или сильно искаженные пирамидальные структуры. Появление рельефа такого вида может быть объяснено превалированием химической составляющей плазмохимического травления по мере удаления от поверхности образца. Дальнейшая оптимизация параметров рельефа, получаемого в результате комбинированного травления, возможна благодаря варьированию режимов применяемых операций.

Ключевые слова: нитрид галлия, рельеф, реактивное ионное травление, жидкостное травление, светоизлучающий диод, светоизлучающий кристалл.

DOI: 10.21883/FTP.2020.10.49952.9465

\section{1. Введение}

В последние годы создаются все более разнообразные приборы на основе широкозонного материала GaN. Если в начале он использовался в основном в светоизлучающих кристаллах синего и ультрафиолетового диапазонов, применяемых в производстве белых светодиодов $[1,2]$ и лазеров $[3,4]$, то в настоящее время большое внимание уделяется также исследованиям в области высокочастотных и высоковольтных применений $[5,6]$. Известно, что высокая химическая стойкость материала затрудняет его травление с целью формирования полупроводниковых приборов на его основе. Наиболее эффективно материал травится в хлорсодержащей плазме или же в щелочных растворах (KOH или $\mathrm{NaOH}$ ). Также возможно проводить травление $\mathrm{GaN}$ в ортофосфорной кислоте $\left(\mathrm{H}_{3} \mathrm{PO}_{4}\right)$, однако скорости травления в ней незначительны. При этом сами подходы к травлению материала могут быть отличными в зависимости от сферы его применения. При разработке высоковольтных и высокочастотных элементов (диодов и транзисторов) востребованы методы, обеспечивающие плоскопараллельное травление материала с наименьшим количеством дефектов, так как при этом сокращается вероятность утечек тока в формируемых приборах. Так, например, авторы работы [7] использовали импульсное фотоэлектрохимическое травление в растворе $\mathrm{NaOH}$ для получения диодов с напряжением пробоя, превышающим 3 кВ, а в работе [8] применение этого же метода позволило увеличить напряжение пробоя диодов до значений, превышающих 3.8 кВ, что на 0.5 кВ превышало, по данным работы, значения напряжения пробоя приборов, сформированных травлением материала $\mathrm{GaN}$ в индуктивно связанной плазме (ICP). В то же время в светоизлучающих приборах, наоборот, часто востребованы поверхности с хорошо развитым рельефом, позволяющим снизить френелевское отражение на границе кристаллов с внешней средой. Это связано с тем, что вследствие высокого показателя преломления материала, из которого изготовлен кристалл, большая часть генерируемого излучения поглощается в самом кристалле, многократно отражаясь от его границ. Среди способов, призванных бороться с негативными последствиями эффекта полного внутреннего отражения, обычно рассматриваются следующие способы: формирование фотонных кристаллов [9,10], текстурированных [11-13] или имеющих градиент показателя преломления прозрачных проводящих контактов $[14,15]$, использование для роста предварительно профилированных подложек $[16,17]$. Анизотропное травление материала GaN является одним из самых эффективных способов создания светорассеивающих поверхностей, способствующих росту квантовой эффективности светодиодов с удаленной ростовой подложкой [18-20]. Кроме этого, процедура удаления непроводящей ростовой подложки обеспечивает возможность создания вертикальных кристаллов, в 
которых контактные площадки располагаются на обеих сторонах гетероструктуры $[19,20]$. Создание рельефа на свободной от контактов части световыводящей поверхности кристалла приводит к увеличению квантовой эффективности светодиодов в несколько раз [19]. В светодиодах флип-чип конструкции [21,22], предполагающих размещение контактных площадок по одну сторону от гетероструктуры, вторая, световыводящая поверхность может быть полностью отведена для создания рельефа. Сравнение свойств вертикальных кристаллов и кристаллов флип-чип конструкции можно найти в статье [23]. По эффективности вывода света использование профилированных подложек несколько уступает анизотропному травлению свободной от ростовой подложки поверхности светодиодного кристалла. В то же время по совокупности факторов, среди которых основным можно назвать простоту технологического процесса изготовления кристалла, рост на профилированных подложках оказывается предпочтительным, что и объясняет более широкое распространение кристаллов синего диапазона, выращенных на профилированном сапфире. При этом обозначившаяся в последнее время тенденция увеличения запроса на светодиоды ультрафиолетового диапазона [24-26] снова заставляет вернуться к исследованиям в области анизотропного травления материала $\mathrm{GaN}$, так как существенное уменьшение длины волны излучения требует пропорционального уменьшения масштабов создаваемого рельефа для поддержания эффективности вывода света из кристалла. В этом случае производство профилированных подложек и изготовление на них светоизлучающих кристаллов может уступить по совокупности факторов производству кристаллов с рельефом на свободной от ростовой подложки поверхности.

В работе [27] рассматривались возможности модификации рельефа реактивным ионным травлением в хлорсодержащей плазме. В то же время известно, что травление свободной от ростовой подложки поверхности в щелочных растворах приводит к образованию гексагональных пирамид вследствие травления материала по выделенным плоскостям (изучение процессов анизотропного травления материала $\mathrm{GaN}$ можно найти, например, в работе [28]). Оптимизация создаваемого рельефа должна приводить к повышению эффективности вывода света, однако возможности модификации рельефа как в случае жидкостного травления, так и при травлении в плазме весьма ограничены. Поэтому естественным являются попытки расширить спектр возможностей за счет применения комбинированного травления, которое будет сочетать в себе последовательно проводимые процессы жидкостного и плазмохимического травления материала. Одной из первых работ, упоминающих комбинированное травление, была статья [29], авторы которой рассматривали склонность к жидкостному травлению в растворах КОН различно ориентированных мезаструктур, сформированных в материале $\mathrm{GaN}$ реактивным ионным травлением в хлорсодержащей плазме, a в работе [30] было проведено сравнение электрооптических характеристик ультрафиолетовых светодиодов, подвергавшихся травлению в растворах гидроксида тетраметиламмония (ТМАН), также являющегося сильным основанием. В настоящей работе мы рассмотрим, как можно модифицировать рельеф сочетанием последовательно проводимых процессов реактивного ионного и жидкостного химического травления. Такой подход помогает расширить область поиска оптимальной морфологии поверхности для вывода излучения с заданной длиной волны.

\section{2. Результаты эксперимента и их обсуждение}

AlGaInN-светодиодные гетероструктуры, использовавшиеся в настоящей работе, выращивались на сапфировых подложках методом газофазной эпитаксии из металлоорганических соединений на установке Е300 производства фирмы Veесо. Гетероструктура содержала следующие слои: нелегированный слой $\mathrm{GaN}$ толщиной $\sim 1$ мкм, слой $n$-GaN толщиной $\sim 3$ мкм, вспомогательную сверхрешетку (СР) из 10 слоев $n$-GaN/n-InGaN (3/2.5 мкм), активную область, состоящую из пяти квантовых ям InGaN толщиной $1.6 \mathrm{Hм}$, разделенных барьерами $\mathrm{GaN}$ толщиной 2 нм, сверхрешетку из 10 пар слоев $p$-AlGaN/GaN и слой $p$-GaN толщиной 0.1 мкм. Удаление сапфировой подложки проводилось с использованием мощного эксимерного $\mathrm{KrF}$-лазера с длиной волны 248 нм. Для этого в предварительно полированных со стороны сапфира пластинах с использованием фотолитографических операций методом реактивного ионного травления (RIE) вытравливались дорожки шириной 0.1 мм на всю глубину гетероструктуры. В результате были сформированы островки с размерами $1.1 \times 1.1$ мм, на которые наносился контакт к $p$-области $\mathrm{GaN}$ состава $\mathrm{Ni} / \mathrm{Au}$. Для переноса гетероструктур на кремниевую подложку контакт усиливался гальваническим золотом толщиной 2 мкм. В дальнейшем структура приваривалась к кремниевой пластине с образованием эвтектического соединения $\mathrm{Au}(97.1$ мас\%) : $\mathrm{Si}(2.9$ мас\%). После удаления ростовой сапфировой подложки островки гетероструктур оставались размещенными на кремниевой пластине $n$-поверхностью вверх. Процесс переноса гетероструктур на кремниевые пластины с удалением сапфировой подложки детально описан в статье [23].

Создание рельефа на освободившейся от ростовой подложки поверхности гетероструктур проводилось с использованием комбинации из следующих видов травления.

Плазмохимическое травление гетероструктур проводилось на установке реактивного ионного травления RDE 300 производства фирмы Alcatel в газовой смеси, состоящей из трех компонентов: $\mathrm{Cl}_{2}, \mathrm{BCl}_{3}, \mathrm{Ar}$. Эксперименты проводились при давлении в вакуумной камере 1 Па, мощность плазменного разряда составляла 25 Вт, а газы подавались в вакуумную камеру таким образом, что соотношение их потоков $\mathrm{Cl}_{2}: \mathrm{BCl}_{3}: \mathrm{Ar}$ составило 6:10:11, т.е. потоки $\mathrm{Cl}_{2}, \mathrm{BCl}_{3}$ и $\mathrm{Ar}$ составили 6, 10 и 11 стандартных кубических см в мин 


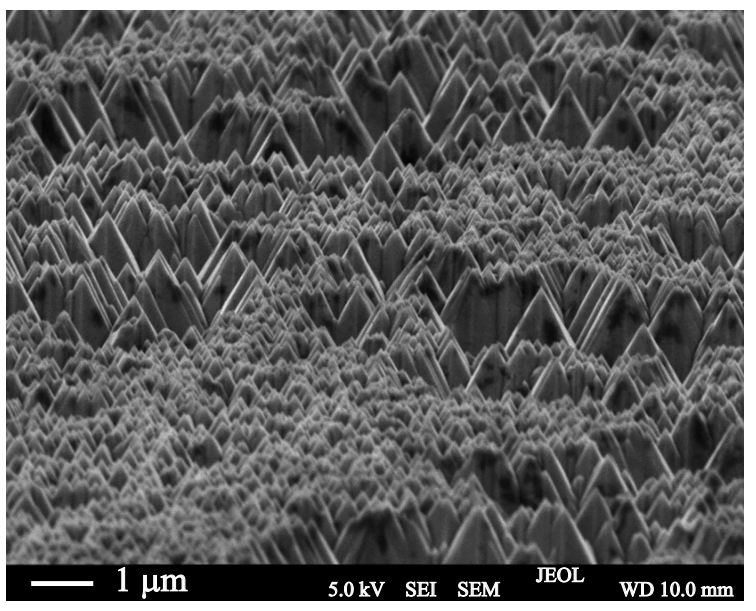

Рис. 1. РЭМ-изображение поверхности $\mathrm{GaN}$ после травления в горячем растворе $\mathrm{KOH}$ в течение 5 мин.

(sccm) соответственно. Этот режим травления приводил к созданию рельефа на свободной от ростовой подложки поверхности гетероструктуры, способствующего максимальному выводу излучения из светодиодного кристалла с длиной волны собственного излучения 460 нм [27]. Следует также отметить, что этот режим используется нами для формирования светодиодных кристаллов при травлении со стороны $p$-поверхности $\mathrm{GaN}$ с целью организации доступа к $n$-области гетероструктуры и разделения кристаллов на пластине. Травлением в этом режиме в настоящей работе были сформированы дорожки в гетероструктуре перед постановкой ее на кремниевую подложку (см. выше).

Жидкостное травление гетероструктур проводилось в $40 \%$ растворе $\mathrm{KOH}$, нагретом до температуры $90^{\circ} \mathrm{C}$, а также в концентрированном растворе $(70 \%)$ соляной кислоты.

Результат травления образцов в течение 5 мин в горячем растворе КОН приведен на рис. 1. Как видим из рисунка, этого времени достаточно для формирования развитого рельефа. На поверхности гетероструктуры сформировались пирамиды различной высоты, характерные для травления в щелочных растворах.

Реактивное ионное травление в хлорсодержащей плазме приводит к появлению тонкого трубчатого рельефа с характерными размерами 150-300 нм (рис. 2). При этом, как обсуждалось в работе [27], могут также наблюдаться элементы микронного размера.

Как показали проведенные эксперименты, комбинация реактивного ионного травления с травлением в растворах КОН приводит к разному результату в зависимости от последовательности применяемых методов травления. Жидкостное травление идет с бо́льшими скоростями, чем плазмохимическое. Травление в хлорсодержащей плазме создает хорошо развитый рельеф с большой площадью поверхности. Его выдержка в растворе щелочи приводит к быстрому исчезновению тонкого рельефа и характерному травлению поверхности по выделенным плоскостям. Таким образом, результат травления в горячем растворе $\mathrm{KOH}$ в течение 3 мин поверхности $\mathrm{GaN}$, предварительно травившейся в хлорсодержащей плазме согласно описанному выше режиму, эквивалентен результату травления в растворе $\mathrm{KOH}$ и не несет информации о стадии предварительного плазмохимического травления (см. рис. 3).

Однако смена порядка в последовательности режимов травления может привести к появлению принципиально новой морфологии поверхности. На рис. 4 приведено изображение поверхности $\mathrm{GaN}$, подвергавшейся 2-минутному травлению в горячем растворе $\mathrm{KOH}$ с последующим травлением в хлорсодержащей плазме в течение 35 мин. Как видим, в результате такого комбинированного травления, поверхность становится покрыта усеченными пустотелыми конусами. Учитывая тонкость стенок получаемого рельефа, можно предположить, что

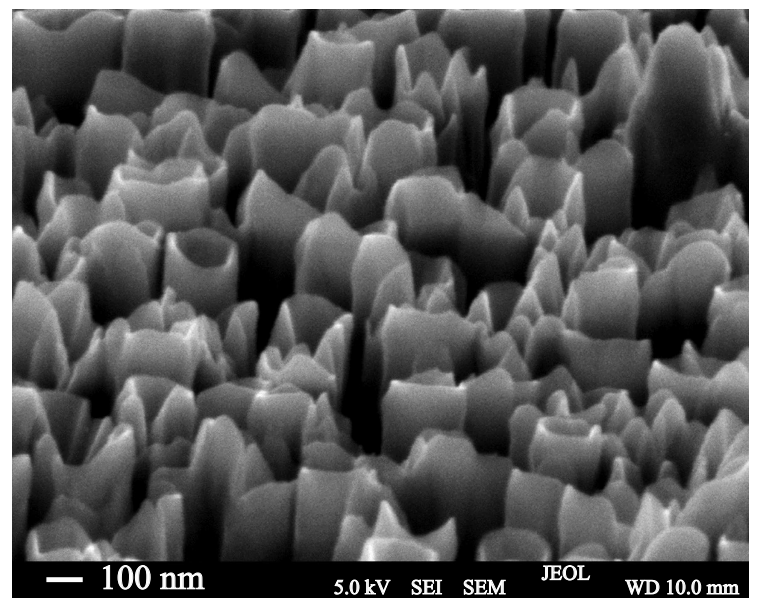

Рис. 2. РЭМ-изображение тонкого рельефа на поверхности образца после травления в течение 45 мин в хлорсодержащей плазме.

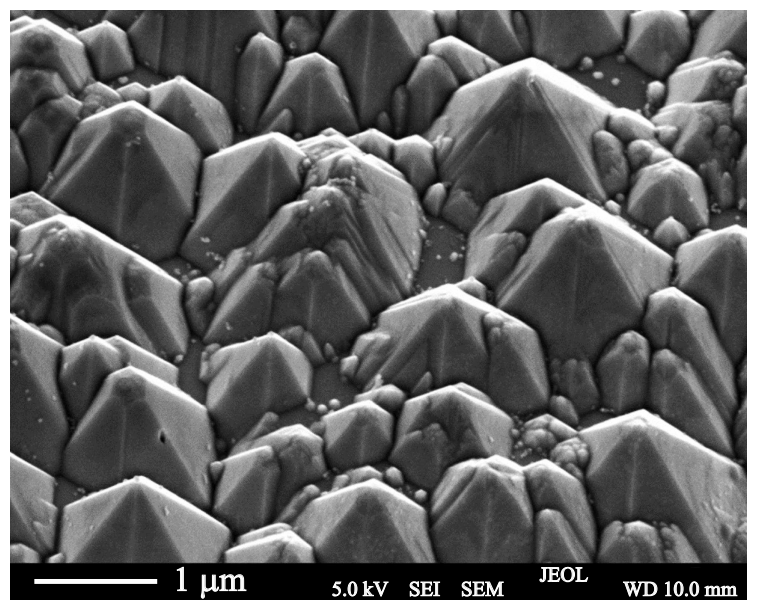

Рис. 3. РЭМ-изображение рельефа на поверхности $\mathrm{GaN}$, возникшего в результате 2-х последовательных стадий травления: в хлорсодержащей плазме в течение 10 мин и $\mathrm{KOH}$ в течение 3 мин. 


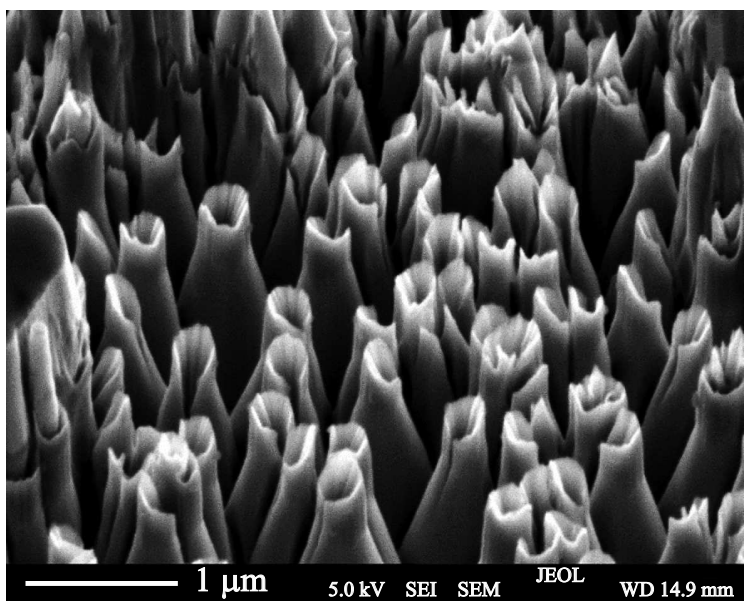

Рис. 4. РЭМ-изображение рельефа на поверхности $\mathrm{GaN}$, возникшего после травления в растворе $\mathrm{KOH}$ в течение 2 мин с последующим травлением в хлорсодержащей плазме в течение 35 мин.

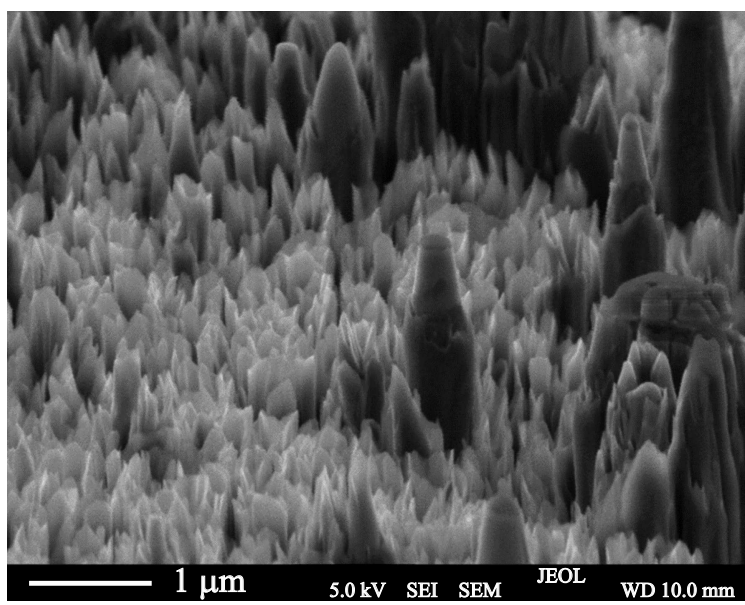

Рис. 5. РЭМ-изображение рельефа на поверхности $\mathrm{GaN}$, возникшего после травления в растворе КОН в течение 2 мин с последующим травлением в хлорсодержащей плазме в течение 70 мин.

такие структуры могут быть востребованы при выводе излучения коротковолновой части спектра. Как было показано в работе [31], структура рельефа, возникающего на стадии плазмохимического травления, зависит от параметров травления. Поэтому варьируя режимы травления каждой из двух последовательных стадий травления, можно изменять параметры создаваемого рельефа, добиваясь более эффективного вывода проходящего через поверхность света. Однако стоит отметить, что дальнейшее значительное увеличение длительности стадии плазмохимического травления приводит к „стиранию“ информации о предварительном жидкостном травлении. Так, например, дополнительные 35 мин реактивного ионного травления структуры, изображенной на рис. 4, приводят к результату, изображенному на рис. 5.
Интересные результаты были получены нами при исследовании комбинации травления образцов в растворе соляной кислоты и реактивного ионного травления. Так как объемный материал $\mathrm{GaN}$ не травится в растворах соляной кислоты, результат комбинированного травления в последовательности $\mathrm{HCl}-\mathrm{RIE}$ полностью идентичен результату, получаемому просто плазмохимическим травлением. В то же время травление в обратной последовательности (RIE-HCl) приводит к неожиданному результату. На рис. 6 приведено изображение поверхности $\mathrm{GaN}$, полученной комбинированным травлением, в котором образец подвергался реактивному ионному травлению в течение 50 мин с последующим травлением в растворе $\mathrm{HCl}$ в течение 5 мин. Из рисунка видно, что тонкий рельеф, образующийся на поверхности $\mathrm{GaN}$ в результате плазмохимического травления (см. рис. 1), оказывается полностью стравленным в течение 5-минутного погружения образца в раствор соляной кислоты, а на поверхности остаются только элементы микронного размера. Это, как правило, объекты цилиндрической формы, переходящие в основании в конические или сильно искаженные пирамидальные структуры, которые по своим параметрам близки к наблюдаемым при травлении в растворах $\mathrm{KOH}$ (рис. 1), что косвенно указывает на то, что при плазмохимическом травлении по мере удаления от поверхности начинает превалировать химическая составляющая, при которой, как обсуждалось выше, травление идет по выделенным плоскостям. В то же время, как видим из рис. 6, выраженная вертикальная направленность плазмохимического травления приводит к появлению цилиндрических элементов на вершинах элементов рельефа. Напомним, что тонкий рельеф, создаваемый на стадии плазмохимического травления, обладает настолько развитой поверхностью, что в отличие от объемного материала он активно травится в соляной кислоте. Таким образом, применение обсуждаемой последовательности в комбинированном травлении привело нас, с одной стороны, к возможности получения

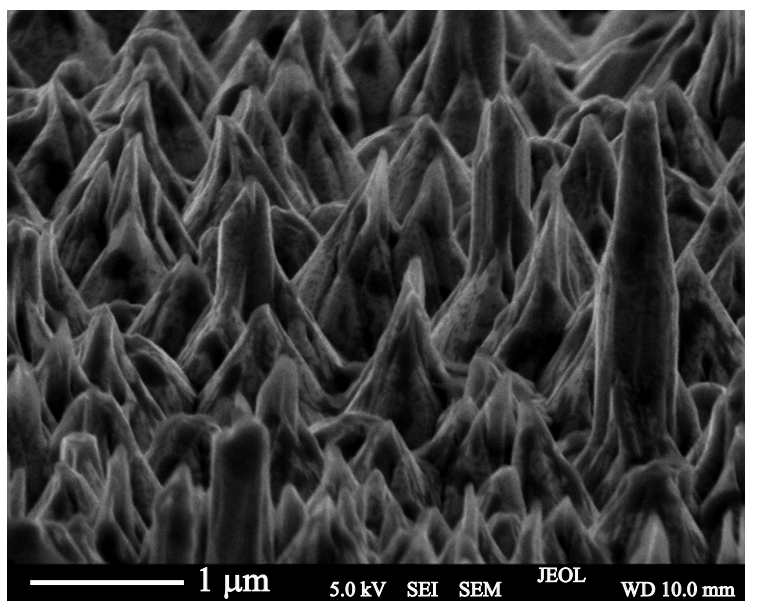

Рис. 6. РЭМ-изображение результата комбинированного травления материала GaN (RIE в течение 50 мин с последующим травлением в растворе $\mathrm{HCl}$ в течение 5 мин). 
нового типа рельефа микронного размера, а с другой к пониманию возможности селективного, зависящего от размеров элементов, травления материала $\mathrm{GaN}$ в растворах соляной кислоты.

\section{3. Заключение}

Таким образом, комбинированное травление свободной от ростовой подложки поверхности $\mathrm{GaN}$, в котором плазмохимическое травление применяется совместно с жидкостным травлением (в растворах $\mathrm{KOH}$ или соляной кислоты), позволяет создавать новые виды рельефа, параметры которого зависят от последовательности выполняемых операций. Так, травление в растворе $\mathrm{KOH}$, за которым следует реактивное ионное травление, приводит к появлению на поверхности усеченных пустотелых конусов, а сочетание реактивного ионного травления с травлением в растворе соляной кислоты формирует на поверхности объекты цилиндрической формы, переходящие в основании в конические или сильно искаженные пирамидальные структуры. Появление такого вида рельефа возможно благодаря селективной способности раствора соляной кислоты к травлению исключительно наноразмерных элементов GaN. Наблюдаемая в этих экспериментах склонность к травлению материала $\mathrm{GaN}$ по выделенным плоскостям при реактивном ионном травлении образца свидетельствует о возрастании химической составляющей по мере удаления от поверхности. Варьирование режимов применяемых в комбинированном травлении операций может привести к оптимизации структуры получаемого рельефа. Результаты работы могут быть интересны не только с точки зрения вывода генерируемого кристаллом излучения, но также при изучении процессов поглощения внешнего излучения, как это происходит в приборах фотовольтаики.

\section{Конфликт интересов}

Авторы заявляют, что у них нет конфликта интересов.

\section{Список литературы}

[1] H. Jia, L. Guo, W. Wang, H. Chen. Adv. Mater., 21, 4641 (2009).

[2] J.K. Sheu, S.J. Chang, C.H. Kuo, Y.K. Su, L.W. Wu, Y.C. Lin, W.C. Lai, J.M. Tsai, G.C. Chi, R.K. Wu. IEEE Photon. Technol. Lett., 15, 18 (2003).

[3] M.C. Schmidt, K.C. Kim, R.M. Farrell, D.F. Feezell, D.A. Cohen, M. Saito, K. Fujito, J.S. Speck, S.P. DenBaars, S. Nakamura. Jpn. J. Appl. Phys., Pt 2, Lett., 46, L190 (2007).

[4] Y.-C. Chi, D.-H. Hsieh, C.-T. Tsai, H.-Y. Chen, H.-C. Kuo, G.-R. Lin. Opt. Express, 23, 13051 (2015).

[5] T. Kachi. Jpn. J. Appl. Phys., 53, 100210 (2014).

[6] A.M. Armstrong, A.A. Allerman, A.J. Fischer, M.P. King, M.S. Van Heukelom, M.W. Moseley, R.J. Kaplar, J.J. Wierer, M.H. Crawford, J.R. Dickerson. Electron. Lett., 52, 1170 (2016).
[7] F. Horikiri, Y. Narita, T. Yoshida. Jpn. J. Appl. Phys., 57, 086502 (2018).

[8] N. Asai, H. Ohta, F. Horikiri, Y. Narita, T. Yoshida, T. Mishima. Jpn. J. Appl. Phys., 58, SCCD05 (2019).

[9] D. Ge, X. Huang, J. Wei, P. Qian, L. Zhang, J. Ding, S. Zhu. Mater. Res. Express, 6, 086201 (2019).

[10] H.H. Yen, H.C. Kuo, W.Y. Yeh. Phys. Status Solidi C, 5, 2152 (2008).

[11] J.H. Kang, J.H. Ryu, H.K. Kim, H.Y. Kim, N. Han, Y.J. Park, P. Uthirakumar, C.-H. Hong. Opt. Express, 19, 3637 (2011).

[12] R.H. Horng, C.C. Yang, J.Y. Wu, S.H. Huang, C.E. Lee, D.S. Wuu. Appl. Phys. Lett., 86, 221101 (2005).

[13] H. Huang, J. Hu, H. Wang. J. Semicond., 35, 084006 (2014).

[14] M.J. Park, C.U. Kim, S.B. Kang, S.H. Won, J.S. Kwak, C.-M. Kim, K.J. Choi. Adv. Opt. Mater., 5, 1600684 (2017).

[15] Л.К. Марков, А.С. Павлюченко, И.П. Смирнова. ФТП, 53, 181 (2019).

[16] Y.J. Lee, J.M. Hwang, T.C. Hsu, M.H. Hsieh, M.J. Jou, B.J. Lee, T.C. Lu, H.C. Kuo, S.C. Wang. IEEE Photon. Technol. Lett., 18, 1152 (2006).

[17] S.-M. Jeong, S. Kissinger, D.-W. Kim, S. Jae Lee, J.-S. Kim, H.-K. Ahn, C.-R. Lee. J. Cryst. Growth, 312, 258 (2010).

[18] Y.J. Sung, M.-S. Kim, H. Kim, S. Choi, Y.H. Kim, M.-H. Jung, R.-J. Choi, Y.-T. Moon, J.-T. Oh, H.-H. Jeong, G.Y. Yeom, H.-H. Jeong, G.Y. Yeom, G.Y. Yeom, G.Y. Yeom. Opt. Express, 27, 29930 (2019).

[19] T. Fujii, Y. Gao, R. Sharma, E.L. Hu, S.P. DenBaars, S. Nakamura. Appl. Phys. Lett., 84, 855 (2004).

[20] D.W. Kim, H.Y. Lee, M.C. Yoo, G.Y. Yeom. Appl. Phys. Lett., 86, 052108 (2005).

[21] J.J. Wierer, D.A. Steigerwald, M.R. Krames, J.J. O'Shea, M.J. Ludowise, G. Christenson, Y.-C. Shen, C. Lowery, P.S. Martin, S. Subramanya, W. Götz, N.F. Gardner, R.S. Kern, S.A. Stockman. Appl. Phys. Lett., 78, 3379 (2001).

[22] S. Zhou, X. Liu, H. Yan, Z. Chen, Y. Liu, S. Liu. Opt. Express, 27, A669 (2019).

[23] Л.К. Марков, И.П. Смирнова, А.С. Павлюченко, М.В. Кукушкин, Е.Д. Васильева, А.Е. Черняков, А.С. Усиков. ФТП, 47, 386 (2013).

[24] X. Liu, Y. Mou, H. Wang, R. Liang, X. Wang, Y. Peng, M. Chen. Appl. Optics, 57, (2018).

[25] Q. Chen, H. Zhang, J. Dai, S. Zhang, S. Wang, J. He, R. Liang, Z.H. Zhang, C. Chen. IEEE Photon. J., 10, (2018).

[26] Y. Muramoto, M. Kimura, S. Nouda. Semicond. Sci. Technol., 29, 084004 (2014).

[27] Л.К. Марков, И.П. Смирнова, М.В. Кукушкин, А.С. Павлюченко. ФТП, 6, 564 (2020).

[28] Y.Y. Lai, S.C. Hsu, H.S. Chang, Y.C.S. Wu, C.H. Chen, L.Y. Chen, Y.J. Cheng. Res. Chem. Intermed., 43, 3563 (2017).

[29] M. Itoh, T. Kinoshita, C. Koike, M. Takeuchi, K. Kawasaki, Y. Aoyagi. Jpn. J. Appl. Phys., 45, 3988 (2006).

[30] H. Wan, B. Tang, N. Li, S. Zhou, C. Gui, S. Liu. Nanomaterials, 9, 365 (2019).

[31] Л.К. Марков, И.П. Смирнова, М.В. Кукушкин, А.С. Павлюченко. ФТП, 6, 564 (2020).

Редактор А.Н. Смирнов 


\section{Combination of Reactive Ion and Chemical Etching as a Method to Optimize the Surface Relief on AIGalnN Heterostructures}

L.K. Markov, I.P. Smirnova, M.V. Kukushkin, A.S. Pavluchenko

loffe Institute, the Russian Academy of Sciences, 194021 St. Petersburg, Russia

Abstract A method, in which reactive ion etching is combined with liquid etching (in solutions of $\mathrm{KOH}$ or hydrochloric acid), is used to produce a relief on the GaN surface previously freed from the growth substrate. The dependence of obtained relief on the sequence of used operations has been studied. It has been shown that etching in a $\mathrm{KOH}$ solution followed by reactive ion etching provides the appearance of truncated hollow cones on the surface. In the experiments, the ability of a hydrochloric acid solution to etch exclusively nanoscaled elements of GaN relief, which are formed by reactive ion etching, has also been found. As a result, reactive ion etching of the sample with subsequent immersion in hydrochloric acid produces on its surface objects with a cylindrical shape, which are transforming into conical or strongly distorted pyramidal structures at the base. The occurrence of a similar relief can be accounted for by the prevalence of the chemical component of reactive ion etching with increasing the distance from the surface of a sample. Further optimization of the parameters of the relief obtained as a result of the combined etching can be implemented by the varying the modes of used operations. 